\title{
Shedding light on racial variations in the outcomes of congenital heart surgery
}

\author{
Roosevelt Bryant III, MD
}

\author{
From the Division of Cardiovascular Surgery, The Heart Institute, Cincinnati Children's Hospital Medical Center, \\ Cincinnati, Ohio. \\ Disclosures: Author has nothing to disclose with regard to commercial support. \\ Received for publication March 5, 2018; accepted for publication March 9, 2018; available ahead of print April \\ $19,2018$. \\ Address for reprints: Roosevelt Bryant III, MD, Pediatric Heart Transplant Program, Cincinnati Children's Hos- \\ pital Medical Center, The University of Cincinnati College of Medicine, 3333 Burnet Ave-MLC 2004, Cincin- \\ nati, OH 45229 (E-mail: Roosevelt.BryantIII@cchmc.org). \\ J Thorac Cardiovasc Surg 2018;156:291 \\ $0022-5223 / \$ 36.00$ \\ Copyright $(2018$ by The American Association for Thoracic Surgery \\ https://doi.org/10.1016/j.jtcvs.2018.03.045
}

"Of all forms of inequality, injustice in health care is the most shocking and inhuman." These are the words of Martin Luther King, Jr, from more than 50 years ago, but they still ring true today. Despite numerous advances in health care and in the surgical management of congenital heart defects, evidence suggests a persistent racial and ethnic disparity in the outcome of children with congenital heart disease. ${ }^{1-3}$ As an example, African American children have been shown to have higher postoperative mortality, longer length of hospital stay, and more postoperative complications than white children undergoing congenital heart surgery. ${ }^{4}$ This disparity in postsurgical survival is seen with Hispanic children as well, and it exists for African American children in other medical disciplines. ${ }^{5}$ African American children are more likely to die of asthma and leukemia, and to have a higher infant mortality rate than white children even in the current era. ${ }^{5}$ Access to care, differences in complexity of procedure, socioeconomic status, and education level have all been suggested as potential causes for this disparity, ${ }^{5,6}$ but no cause has definitively been found.

In a thought-provoking and thorough analysis, Chan and colleagues $^{7}$ begin to shed light on the cause of ethnic and racial disparity after congenital heart surgery. Using a large multi-institutional administrative database, they analyzed racial variations in the use of extracorporeal membrane oxygenation (ECMO) after congenital heart surgery. Their hypothesis was that differences in the use of ECMO as a postoperative support modality may lead to differences in postoperative survival. The findings are sobering. African American children were more likely to die without postoperative ECMO support even though the authors were unable to demonstrate any difference in contraindications to ECMO or any difference in disease complexity based on Risk Adjustment for Congenital Heart Surgery score between races. Patients of other race and those with government insurance had increased mortality after ECMO and

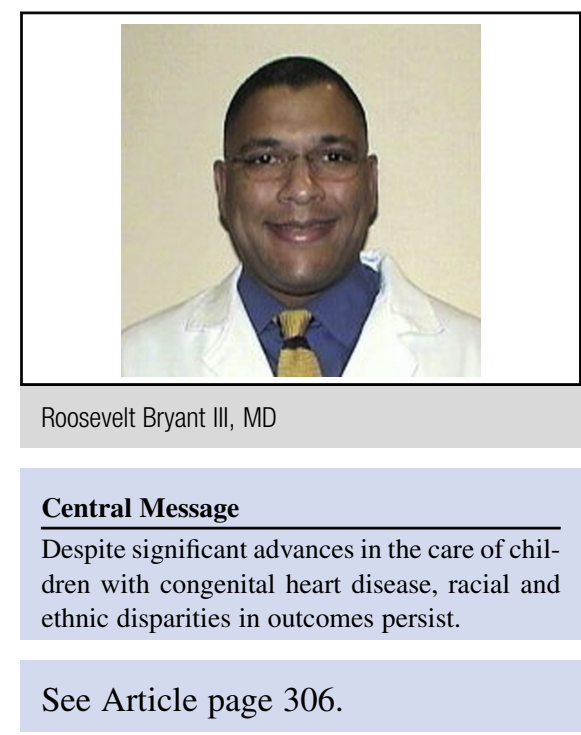

showed variations in the use rate. ${ }^{7}$ These data are revealing, but what is the reason for the variation? The authors opine implicit bias as a cause but acknowledge that it is difficult to prove. That may be so, but many authors believe implicit bias lies at the heart of physician behavior that causes differences in the application of medical therapies across racial and socioeconomic lines. ${ }^{8,9}$ Until the medical community embraces this harsh reality and makes changes, the words of Dr King will continue to ring true.

\section{References}

1. Nembhard WN, Ping X, Ethen MK, Fixler DE, Salemi JL, Canfield MA. Racial/ ethnic disparities in timing of death during childhood among children with congenital heart defects. Birth Defects Res A Clin Mol Teratol. 2013;97:628-40.

2. Benavidez OJ, Gauvreau K, Jenkins KJ. Racial and ethnic disparities in mortality following congenital heart surgery. Pediatr Cardiol. 2006;27:321-8.

3. Flores G, Escala MK, Hall BG. Dead wrong: the growing list of racial/ethnic disparities in childhood mortality. J Pediatr. 2015;166:790-3.

4. Dibardino DJ, Pasquali SK, Hirsch JC, Benjamin DK, Kleeman KC, Salazar JD et al. Effect of sex and race on outcome in patients undergoing congenital heart surgery: an analysis of the Society of Thoracic Surgeons Congenital Heart Surgery database. Ann Thorac Surg. 2012;94:2054-60.

5. Oster ME, Strickland MJ, Mahle WT. Racial and ethnic disparities in postoperative mortality following congenital heart surgery. J Pediatr. 2011;159:222-6.

6. Gonzales PC, Gauvreau K, Demone JA, Piercey GE, Jenkins KJ. Racial and ethnic differences in mortality for congenital heart surgery in children may reflect unequal access to care. Pediatr Cardiol. 2003;24:103-8.

7. Chan T, Barrett CS, Tjoeng YL, Wilkes BS, Bratton SL, Thiagarajan RR. Racial variations in extracorporeal membrane oxygenation use following congenital heart surgery. J Thorac Cardiovasc Surg. 2018;156:306-15.

8. Hall WJ, Chapman MV, Lee KM, Merino YM, Thomas TW, Payne BK, et al. Implicit racial/ethnic bias among healthcare professionals and its influence on healthcare outcomes: a systematic review. Am J Public Health. 2015;105:e60-76.

9. Sabin JA, Rivara FP, Greenwald AG. Physician implicit attitudes and stereotypes about race and quality of medical care. Med Care. 2008;46:678-85. 